European Journal of Business and Innovation Research

Vol.8, No.1.pp. 43-51, January 2020

Published by ECRTD-UK

Print ISSN: 2053-4019(Print), Online ISSN: 2053-4027(Online)

\title{
THE IMPACT OF THE RISING COSTS OF GASOLINE ON AUTOMOBILES OWNERS IN SAUDI ARABIA
}

\section{Mohammed S Mirah ${ }^{1}$, Youssif Albarmawi ${ }^{2}$, Dr. Mohammad Zulfeequar Alam ${ }^{3}$}

1. Master of Business Administration (MBA) Student, College of Business Administration (CBA), University of Business and Technology (UBT), Jeddah 21448, Kingdom of Saudi Arabia (Corresponding Author)

2. Master of Business Administration (MBA) Student, College of Business Administration (CBA), University of Business and Technology (UBT), Jeddah 21448, Kingdom of Saudi Arabia

3. Associate Professor, Department of Marketing, College of Business Administration (CBA), University of Business and Technology (UBT), Jeddah 21448, Kingdom of Saudi Arabia, Email: zulfeqarm@ubt.edu.sa

\begin{abstract}
This research objective is to study the behavior of people and cars users to determine the changing trends and behaviors of customers caused by the new revised prices of oil derivatives and gasoline that was supported by the Saudi Arabian government for a very long period. A survey sample of 361 users was collected randomly within the 2 major cities on the western region of Saudi Arabia; Makkah and Jeddah through survey monkey using structured questionnaire. Data were gathered, analyzed with suitable statistics and later on interpreted accordingly. It was found that more than 35\% survey participant are not changing their cars driving habits, regardless of the rising cost of gasoline - on the other hand, the taken sample certainly showed a reasonable interest towards the consideration of using economy cars- perhaps, electrical/hybrid cars market has a big near future as a potential market. It is also significant to mention that this paper may be beneficial in revealing another field of studies especially for cars companies to know the purchasing power of local consumers.
\end{abstract}

KEYWORDS: rising costs, gasoline, automobiles owners, Saudi Arabia

\section{INTRODUCTION}

Nowadays, cars are essential transportation method in Saudi Arabia due to many social, environmental and cultural factors. To facilitate, the geographical location of the Kingdom, in addition to the wide structure of cities and regions and the lack of other transportations options. Furthermore, being culturally conservative and not considering public transportation busses as preferred option for most. Being considerably sunny and hot in most of the regions is also a deciding factor. All above factors and some more played a crucial role to make cars the most used and preferred transportation way for all.

Along with that, and according to the very promising vision 2030 to heal economically and to produce a diversified GDP from many resources using the right resources. A decision to cut some 
European Journal of Business and Innovation Research

Vol.8, No.1.pp. 43-51, January 2020

Published by ECRTD-UK

Print ISSN: 2053-4019(Print), Online ISSN: 2053-4027(Online)

financial support off oil derivatives such as gasoline and cars fuel may be a concern for some, and it might even change some cars users driving behaviors and habits. Leading to a new market trends perhaps would lower the purchase of gasoline by Saudi drivers. And optimize the use for natural resources.

The fully hybrid and electrical cars may raise and shine as a trend in the very near future, wherein the semi hybrid and energy saving kind of cars are already seen in good numbers by many automobiles' manufacturers. This paper is targeting to mainly explore and study the impact of the raised gasoline costs on cars users within Saudi Arabia; the driving habits and the consideration of switching to economy and energy saving cars.

\section{LITERATURE REVIEW AND HYPOTHESES}

The increase in gasoline price represent a challenging situation to most car drivers. According to Cadie Thompson, if the price of oil keeps on increasing, drivers in America will have to change their behavior in driving as well as changing the type of cars they are driving (Thompson, 2017). Furthermore, (Folger, 2011) mentioned that the increase in volatile oil price will lead people to spend less amount of money on other goods or services and consequently that will affect the overall economy of a country. In. A similar study to (Folger,2011), (Newman, 2012) had also implied that there was a negative relationship between increasing gas price and the economic condition in a country. In contrast, (Wihbey, 2015) studied the inverse impact which is the impact of declining gas price on American consumers and he found that the decrease in the price of a good such as gasoline will have a positive impact on drivers' savings and the overall economy of a nation. On the other hand, in 2015, Kendrick oil company highlighted that the increase in oil price will reduce the demand for cars industry. Walsh, Enz, Canina, 2004, had also implied in their study that there was an inverse relationship between the increasing the price of goods or services and the demand for these goods and services. From a different point of view, increasing the gasoline could also have negative impact on those who do not own cars but use the public transportation such as taxies or busses and make them pay more than the standard price (Sawhill, 2012). As a confirmation to those findings, Visa business and economic insight in 2015 had agreed that the increase in gasoline price might lead the car owners to consume less of it. On a different study that was done by The association for convenience \& fuel retailing (NACS, 2017) which focused on gasoline consumer's behavior towards the increase of its price, NACS ensured that the increase in the fuel price gives a negative indication by car drivers which made the use a lot less of gasoline compared to what they used to consume.

Once again, in 2013, a study conducted by (T. Anderson, Kellogg and M. Sallee, 2013) agreed that there is an inverse relationship between the increase of oil prices and the purchasing frequency of the car driver. On the contrary, the research conducted by (Eia.gov, 2017) that indicated levels of gasoline consumption could be negatively affected by the increase of its price. In addition, (Hederman, 2017) has stated that the increase of tax for gasoline price would surely harm both the overall countries' economy as well as individuals and car driver's income. Also, (Reizenstein and Barnaby, 2017) have found out in their study that most automobiles owner got affected and purchased less of gasoline due to the increase of its price. J.Sauer, 2007 has also confirmed that 
European Journal of Business and Innovation Research

Vol.8, No.1.pp. 43-51, January 2020

Published by ECRTD-UK

Print ISSN: 2053-4019(Print), Online ISSN: 2053-4027(Online)

such a relationship between the increase of a good price such as gasoline and the purchase pattern must be inversed. On the other hand, (E.Millington, 2017) has concluded in his study that the lower the gasoline price, the more car drivers are motivated to purchase or consume it. However, for the sake of this study, an investigation was conducted regarding the increase of gasoline or oil price and the response towards that issues from automobiles owners in The Kingdom of Saudi Arabia

\section{METHODOLOGY OF THE RESEARCH}

3.1 Research subject: An exploratory study of 361 respondents on car users were taken to know impact of raised gasoline price in Saudi Arabia. Through convenience sample 950 participants were contacted to respond the survey using the structured questionnaire through survey monkey online tools. It is noted that all of them were car users. However, it was found that the only 361 samples were usable and taken for the study.

3.2 Research used criteria:

3.2.1- Admitting the problem: A lot of car owners in Saudi Arabia nowadays are suffering from such an increase in the price of gasoline.

3.2.2- Identifying the problem: By evaluating the responses of automobiles owners towards the rise in gasoline costs.

3.2.3- Planning for research design: For the sake of this research, an electronic survey was designed and distributed on "Survey Monkey" among social media in Saudi Arabia.

3.2.4- All 950 research raw population were asked to fill up a structured questionnaire of eleven questions that included: age, number of cars owned, the average consumption of gasoline, the average amount paid for gasoline consumption, the concern of increasing gasoline price, the consumption of gasoline after the price increment, the consideration of buying an economical car in, income, if consumption is reduced and weather if the increase in the gasoline price will harm their budget.

3.2.5- Collecting data: After the survey's results data were collected, (primary data) and secondary data was found from online articles to support this paper's objectives.

3.2.6- Analysis of data: The collected data was analyzed through descriptive suitable descriptive statistical analysis.

3.2.7- Preparing a report: After the data collection and analysis the all contents of the study were all gathered to establish this research report and the conclusion and recommendations were written for decision making.

\section{ANALYSIS OF THE RESULTS}

After distributing the electronic surveys, the responses were collected for further analysis. The major findings follow:

a) Around $50 \%$ from the total population were between the age of 25 and 35 years old while a minor count of approximately $6 \%$ were above 45 years old. The other range of ages such as: (18$22),(23-25)$ and (36-45) years old showed an average of $15 \%$ from the overall population as can be illustrated in figure1.

The major 50\% represents normally the age of post graduates scholars who are more tempted by academic materials and survey, as well as being electronic and online survey. 


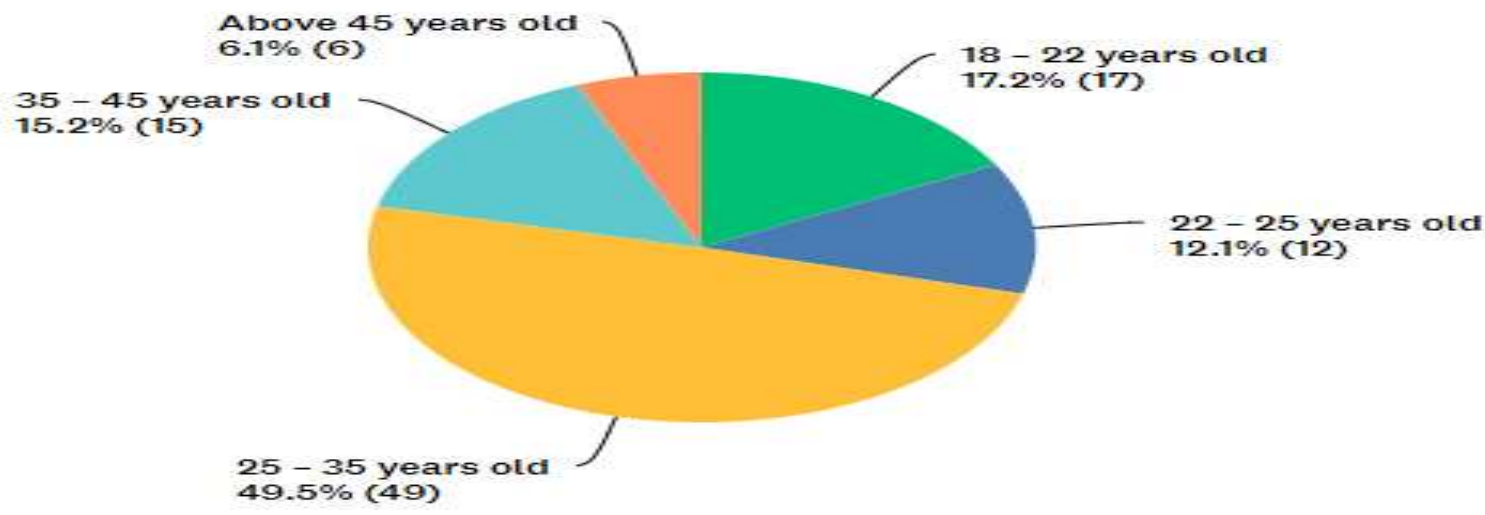

Figure 1: Age of car owner's sample.

b) When the car owners were asked about the number of cars they had, the majority of $45 \%$ replied they owned only one car while $39 \%$ of the drivers said that they had two cars and only $4 \%$ confirmed having more than 3 cars. A $55 \%$ of the sample own more than one care which reflects cars are the primary transportation mean in Saudi Arabia, however, a free time riding can also be sensed from this stat especially when co-evaluated with the young age of participants.

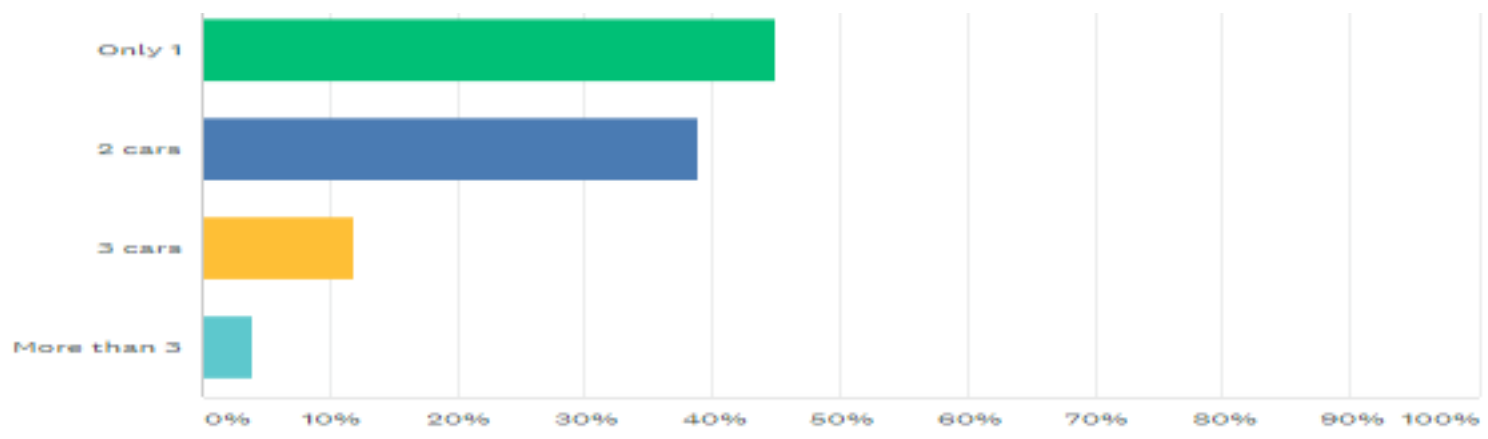

Figure 2: The number of cars owned by Saudi drivers.

c) On Average of $16.6 \%$, the car owners in Saudi Arabia were welling to fill up their gasoline's tanks with a range between (40-300) liters a week and that might be dependent on the needs or wants of the frequency of using their cars. 


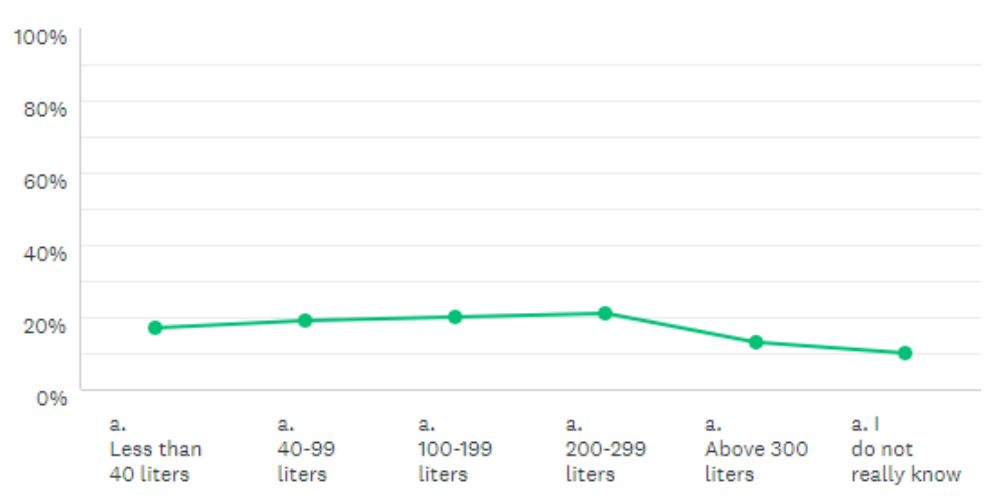

Figure 3: The amount of gasoline consumed by Saudi drivers.

d) 50\% of Saudi car owners preferred to spend an amount between (50-200) Saudi Riyals on gasoline per week while 32\% spent between (201-350) Saudi Riyals where it suits if co-evaluated with having a 55\% to own more than 1 car. Considering the change in gasoline price with the good percentage to drive more than 1 car; the economy and energy saving kind of vehicles sounds more tempting especially when occupied with the technology available in other kinds of cars.

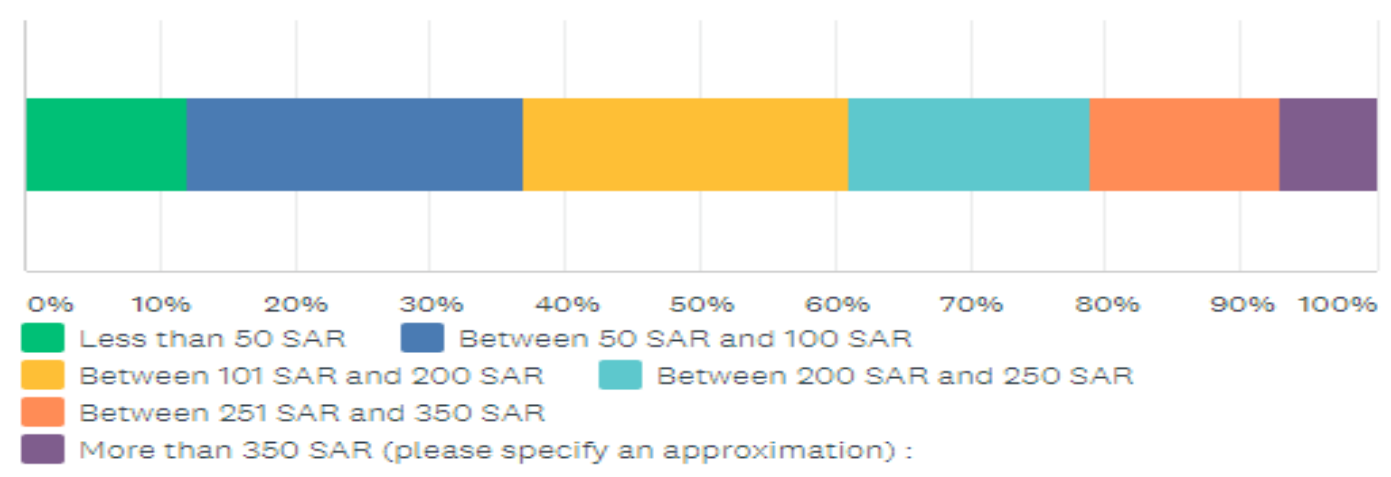

Figure 4: The amount of cash spent on gasoline per month.

e) The level of concern towards the increase of gasoline prices was one of the major objectives of this study. Surprisingly, it seemed like Saudi drivers were not truly concerned about the increment in gasoline prices. Maybe, it is a proportion to the changed driving culture. As noticed, $38 \%$ of the sample respondents were not very concerned about the raise is followed by $18 \%$ That were not concerned about this. On the other hand, $20 \%$ were somewhat concerned and $13 \%$ were neutral and only $11 \%$ which is the smallest percentage were very concerned about gasoline price. 
Print ISSN: 2053-4019(Print), Online ISSN: 2053-4027(Online)

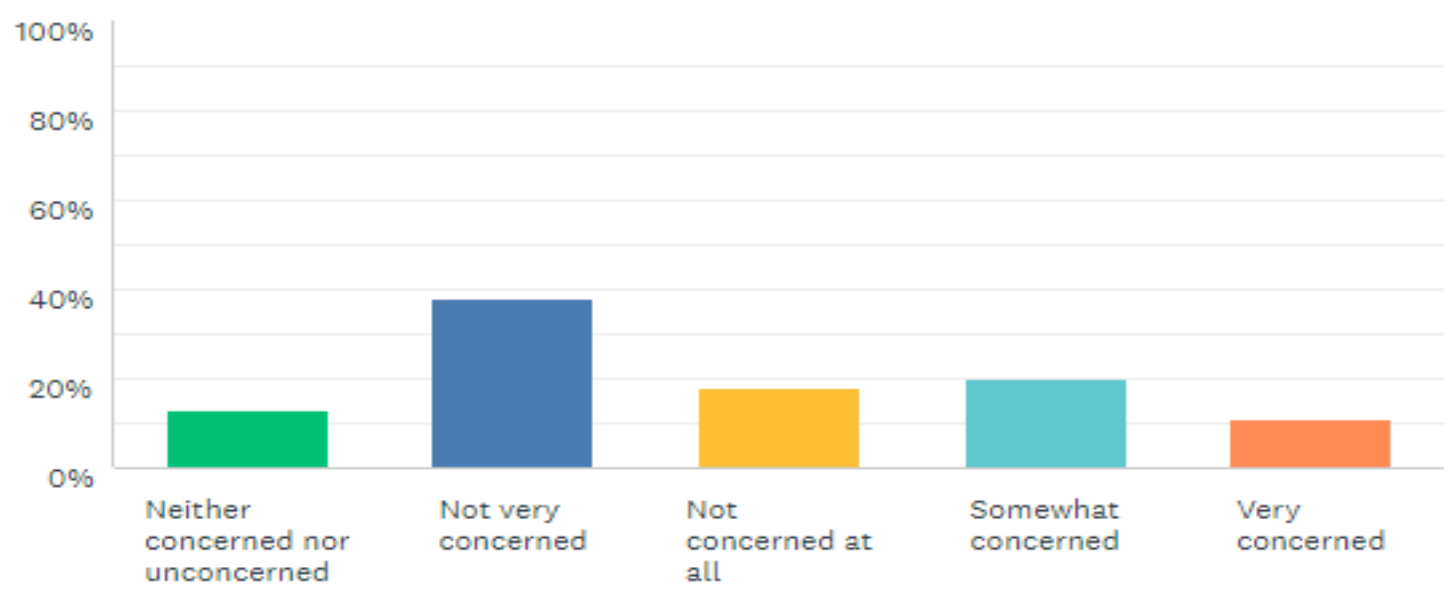

Figure 5: The level of concern

f) When the car owners were asked about their opinion about considering buying economical automobiles in the future, they replied the following: $37 \%$ might consider switching to economical car in the future, $24 \%$ would consider buying such cars and $27 \%$ were not really interested in changing the type of cars they were currently driving. Reflecting that more than $60 \%$ as per this paper are open to the idea of having economy cars and energy savers, however, the other percentage have doubts due to many common reasons such as being loyal to a brand or speed and acceleration concerns. Wherein, there is a big area to improve and thrive within the cars industry market in the very near future.

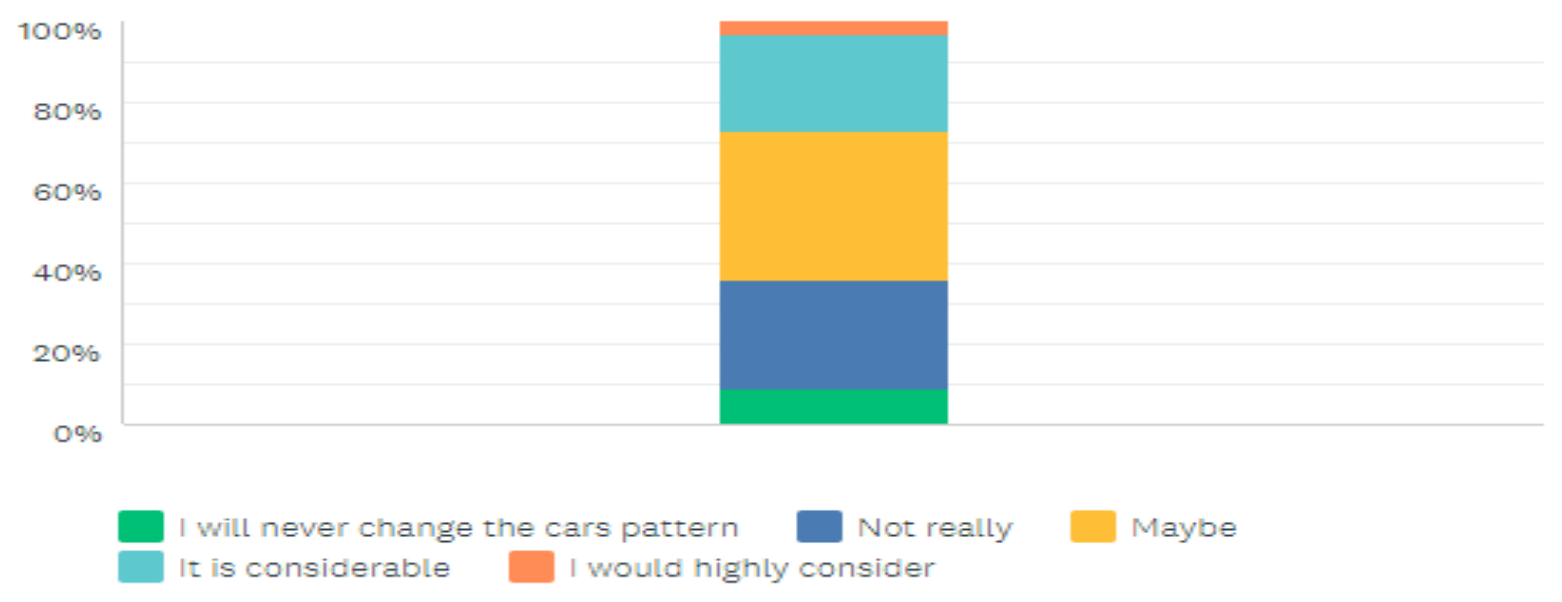

Figure 6: The responses for considering economical car.

g) An approximate percentage of 36 would probably reduce gasoline waste or in other words probably would reduce the free time car tours. On the other hand, 26 car drivers were not sure if they would minimize the use of gasoline and $16 \%$ of drivers said that they would reduce the waste. 
The results had indicated that car owners in Saudi Arabia are motivated to drive their cars less free time tours.

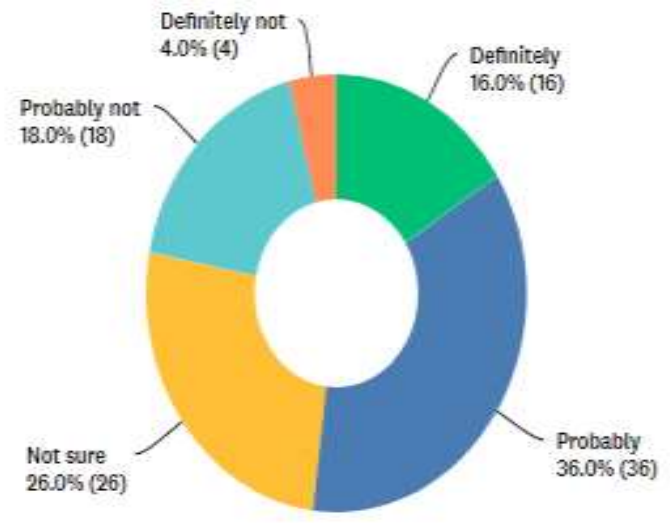

Figure 7: Automobiles owners' reaction towards reducing the gasoline waste.

h) With a percentage of $64 \%$ from participants having a monthly income of 10,000 SAR and less, reflecting the medium to low income class, most of them ensured that gasoline cost will have a negative impact on their budget with a percentage of $36 \%$ voting yes. And a percentage of $12 \%$ giving it a highly yes in total of $48 \%$. Nevertheless, considering above stats the driving culture has a high probability to be optimized and to a start to use cars more efficiently Those findings are demonstrated in the following two graphs.

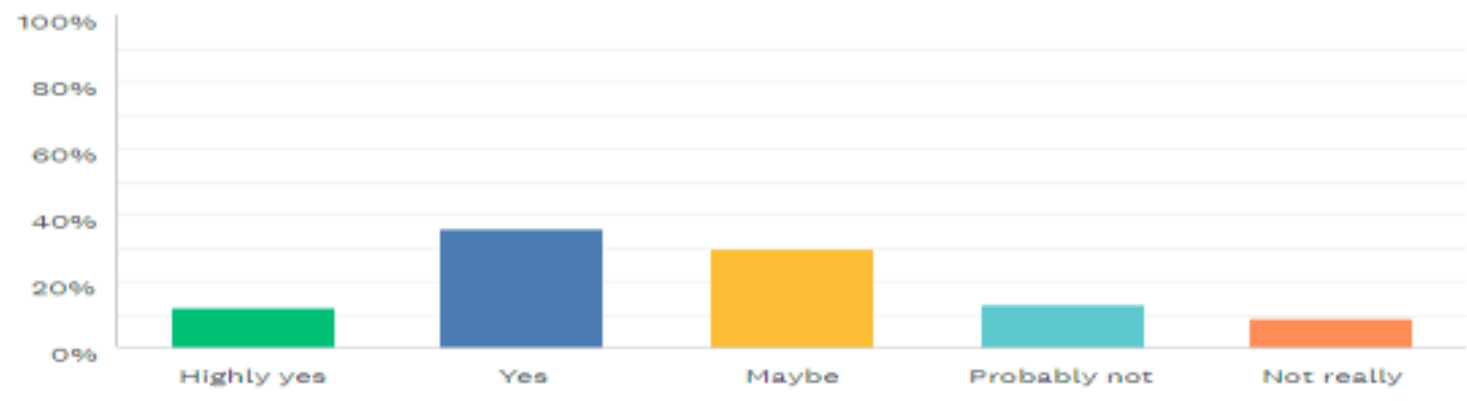

Figure 9: The harm on car owners' budget.

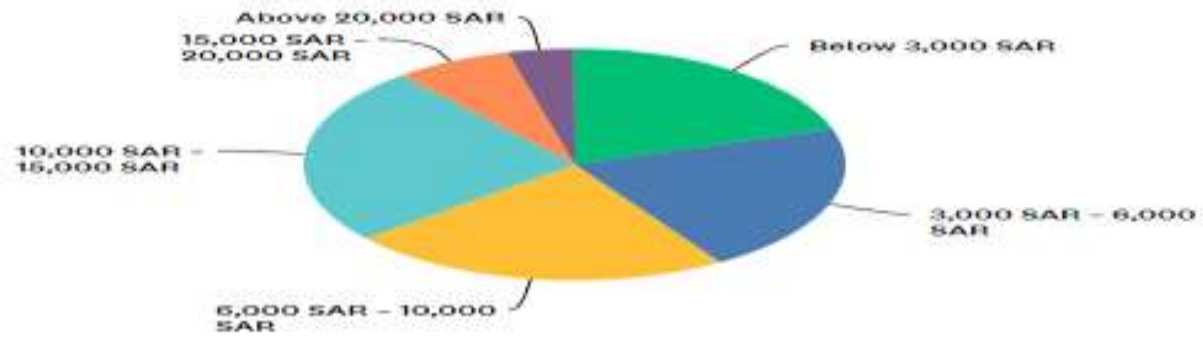

Figure 10: Saudi automobiles owners' intervals of income. 
European Journal of Business and Innovation Research

Vol.8, No.1.pp. 43-51, January 2020

Published by ECRTD-UK

Print ISSN: 2053-4019(Print), Online ISSN: 2053-4027(Online)

\section{CONCLUSION AND RECOMMENDATIONS}

As a conclusion, the increase in the price of goods and services could be considered as a growing phenomenon in the twenty first century that most societies suffer from. However, the oil derivatives raising cost impact will be limited to cars divers and consumers as automobiles retailers will be impacted to. This work is mainly focused on the impact of increasing gasoline's price on users in Saudi Arabia and the result of the research showed a trending behavioral driving culture changes, a more sufficient use of automobiles with a reflection on the economy generally and cars market in particular. However, there are some suggestions which may be useful for future references if a similar research is conducted:

1- The study should include a larger number of samples in a wider geography within different regional areas.

2- The survey should include some questions that give population and participants the freedom to express themselves

3- An open-ended questions and scaled questions may have to be included.

4- The follow up or feedback is necessary after conducting the survey and analyzing the results in order to provide the respondents with the outcome so their level of awareness is to be increased.

5- To minimize the number of errors obtained from respondents, the electronic survey should specify one attempt for each participant in order to avoid repetition of information and receive more accurate results.

\section{References}

1- Thompson, C. (2017). Rising gas prices are a growing threat to the American way of life. [online] Business Insider. Available at: http://www.businessinsider.com/how-rising-gasprices-impact-economy-2017-3.

2- Folger, J. (2017). How Gas Prices Affect The Economy.[online] Investopedia. Available at: http://www.investopedia.com/financial-edge/0511/how-gas-prices-affect-theeconomy.aspx.

3-Newman, Google.com.sa. (2012). The idea of university. [online] Available at: https://www.google.com.sa/url?sa=t\&rct=j\&q=\&esrc=s\&source=web\&cd=1\&ved=0ahU KEwi-

8Le4quTXAhUEVRoKHYe7A3gQFggnMAA\&url=http\%3A\%2\%2Fwww.csun.edu\%2F hceng028\%2FEnglish\%2FSp15\%2Fnewman.pdf\&usg=AOvVaw3tGLwzCfBGbBZbZ MIzWpJ1.

4-Wihbey, J. (2017). Gas prices and their societal effects: Health, driving, economics and policy Journalist's Resource. [online] Journalist's Resource. Available at: https://journalistsresource.org/studies/environment/energy/gas-prices-effects-healthdriving-economics-policy.

5- Walsh, K., A. Enz, C. and Canina, L. (2004). The Impact of Gasoline Price Fluctuations on Lodging Demand for US Brand Hotels. [online] Available at: https://www.google.com.sa/url?sa=t\&rcz=j\&q=\&esrc=s\&source=web\&cd=10\&cad=rja\& 
European Journal of Business and Innovation Research

Vol.8, No.1.pp. 43-51, January 2020

Published by $\boldsymbol{E C R T D}-\boldsymbol{U K}$

Print ISSN: 2053-4019(Print), Online ISSN: 2053-4027(Online)

uact=8\&ved=0ahUKEwjHy8ibl-

TXAhXNCuwKHThmDwQQFghkMAk\&url=http\%3A\%2F\%2Fscholarship.sha.cornell.e du\%2Fcgi\%2Fviewcontent.cgi\%3Farticle\%3D1582\%26context\%3Darticles\&usg=AOvV aw2AAD1GaeNJtEFt-dxGt0KA.

6- Kendrick Oil. (2017). The Effects Of Supply And Demand When Oil And Gas Price Increase Kendrick Oil. [online] Available at: https://www.kendrickoil.com/the-effects-of-supplyand-demand-when-oil-and-gas-price-increase/ .

7- Sawhill, I. (2017). How Higher Gas Prices Hurt Less Affluent Consumers and the Economy. [online] Brookings. Available at: https://www.brookings.edu/opinions/how-higher-gasprices-hurt-less-affluent-consumers-and-the-economy/ .

8- Usa.visa.com. (2017). Access Denied. [online] Available at: https://usa.visa.com/dam/VCOM/download/partner-with-us/gas-price-insight.pdf.

9- Nacsonline.com. (2017). Gas Prices Affect Consumer Sentiment | NACS Online - Your Business - NACS Retail Fuels Reports - 2015 NACS Retail Fuels Report - Consumer Research. [online] Available at: http://www.nacsonline.com/YourBusiness/FuelsReports/2015/ConsumerResearch/Pages/ Gas-Prices-Affect-Consumer-Sentiment.aspx.

10- T. Anderson, S., Kellogg, R. and M. Sallee, J. (2013). What do consumers believe about future gasoline prices?. [online] Nature.berkeley.edu. Available at: https://nature.berkeley.edu/ sallee/draft-inpress.pdf.

11- Eia.gov. (2017). Factors Affecting Gasoline Prices - Energy Explained, Your Guide To Understanding Energy - Energy Information Administration. [online] Available at: https://www.eia.gov/energyexplained/index.cfm?page=gasoline_factors_affecting_prices.

12- Hederman, R. (2017). An Increase in the Gas Tax Would Hurt Consumers and Slow the Economy. [online] The Heritage Foundation. Available at: http://www.heritage.org/taxes/report/increase-the-gas-tax-would-hurt-consumers-andslow-the-economy..

13- Reizenstein, R. and Barnaby, D. (2017). Assessing the Potential Effects of Differential Price Increases on Gasoline Usage. [online] Acrwebsite.org. Available at: http://www.acrwebsite.org/volumes/9618/volumes/v06/NA-06.

14- J.Sauer, W. (2007). FUEL EXCISE TAXES AND CONSUMER GASOLINE DEMAND: COMPARING AVERAGE RETAIL PRICE EFFECTS AND GASOLINE TAX EFFECTS. [online] Repository.library.georgetown.edu. Available at: https://repository.library.georgetown.edu/bitstream/handle/10822/555798/etd_wjs24.pdf; sequence $=1$.

15- E.Millington, S. (2017). The Effect of Oil Price Declines on Consumer Prices. [online] clevelandfed. Available at: https://www.clevelandfed.org/newsroom-andevents/publications/economic-trends/2014-economic-trends/et-20141119-the-effect-ofoil-price-declines-on-consumer-prices.aspx. 